\title{
Applied optimization in manufacturing and services (APPOPT-2008)
}

\author{
Jairo R. Montoya-Torres • Alejandra Gomez-Padilla
}

Published online: 10 July 2010

(C) Springer Science+Business Media, LLC 2010

This special section is related to selected papers from the "Applications Track" of the Ninth International Conference on Approximation and Optimization in the Caribbean (APPOPT2008) held in San Andres Islands, Colombia, March 2-7, 2008 (http://matematicas.univalle. edu.co/ appopt2008/). The APPOPT conference series aims to bring together mathematicians, engineers, and other specialists from a variety of related disciplines, who are at the forefront of their research fields, to exchange original ideas and present high-quality scientific research related to the development of optimization and approximation theory, models, algorithms, and their applications to both theoretical and complex real-life problems. The numerous research papers presented at APPOPT-2008 included a significant amount of research that addressed both manufacturing-oriented and service-oriented problems. Submission to this special section was open to papers related to the topic but not necessary presented at the conference venue. Eleven papers, selected for the quality of both the abstract and the presentation, participated in the evaluation process for this special volume. Only four papers were finally accepted after completing the rigorous traditional peer-review process of the journal for scientific merit. These papers present applications of optimization techniques to solve realistic optimization problems.

The guest editors would first like to acknowledge Professor Endre Boros, Editor-in-Chief of the Annals of Operations Research, for fully supporting this editing project, as well as Professor Olga Vasilieva, Chair of the APPOPT-2008 Organizing Committee. Mrs. Katie D'Agosta, Managing Editor of the Annals of Operations Research, has to be acknowledged

\footnotetext{
J.R. Montoya-Torres $(\bowtie)$

Escuela Internacional de Ciencias Economicas y Administrativas, Universidad de La Sabana,

Km 7 autopista norte de Bogota, D.C., Chia, Cundinamarca, Colombia

e-mail: jairo.montoya@unisabana.edu.co

A. Gomez-Padilla

Department of Industrial Engineering, CUCEI-University of Guadalajara, Av. Revolucion No. 1500, Guadalajara, Jalisco, Mexico

e-mail: alejandra.gomez@cucei.udg.mx
} 
as she was always behind the administrative issues of the publication process of this special section. Finally the guest editors wish to acknowledge the anonymous referees for their help with the review process. 